\title{
Treatment of COVID-19 pneumonia with glucocorticoids (CORTIVID): a structured summary of a study protocol for a randomised controlled trial
}

Iñigo Les Bujanda ${ }^{1 *} \mathbb{D}$, Jose Loureiro-Amigo², Ferran Capdevila Bastons ${ }^{3}$, Iñaki Elejalde Guerra?', Javier Anniccherico Sánchez ${ }^{1}$, Anna Murgadella-Sancho ${ }^{4}$, Ruth García Rey ${ }^{5}$, Julián Librero López ${ }^{6}$ and Julio Sánchez Álvarez

\begin{abstract}
Objectives: The aim of this study is to assess the effectiveness and safety of glucocorticoid infusion pulse therapy to improve the clinical outcomes of patients with COVID-19 pneumonia with elevated inflammatory biomarkers.

Trial design: A parallel-group quadruple-blind (participant, intervention provider, outcome assessor and data manager), randomised controlled trial.

Participants: All patients admitted to hospital due to COVID-19 pneumonia will be considered eligible. Potential candidates will be identified and consecutively included in the emergency room or in the COVID-19 admission wards of two hospitals in Spain: Complejo Hospitalario de Navarra (Pamplona) and Hospital Moisès Broggi (Sant Joan Despí, Barcelona).

Inclusion criteria are: 1) age $\geq 18$ years old; 2) diagnosis of SARS-CoV-2 pneumonia confirmed by reverse transcriptase polymerase chain reaction (RT-PCR) of nasopharyngeal swabs or sputum in accordance with the recommendations of the Spanish Ministry of Health; 3) history of symptoms compatible with COVID-19 $\geq 7$ days; 4) hospital admission; 5) at least one of the following: C-reactive protein (CRP) $>60 \mathrm{mg} / \mathrm{dL}$, interleukin-6 (IL-6) $>40 \mathrm{pg} /$ $\mathrm{mL}$, and/or ferritin $>1000 \mu \mathrm{g} / \mathrm{L}$; and 6) provision of informed consent.

Exclusion criteria are: 1) allergy or contraindication to any of the drugs under study; 2$)$ oxygen saturation $\left(\mathrm{SpO}_{2}\right)<$ $90 \%$ (in air ambient) or partial pressure of oxygen in arterial blood $\left(\mathrm{PaO}_{2}\right)<60 \mathrm{mmHg}$ (in ambient air) or $\mathrm{PaO}_{2} / \mathrm{FiO}_{2}$ $<300 \mathrm{mmHg}$; 3) ongoing treatment with glucocorticoids, or other immunosuppressants, including biologics for another indication; 4) decompensated diabetes mellitus; 5) uncontrolled hypertension; 6) psychotic or manic disorder; 7) active cancer; 8) pregnancy or breastfeeding; 9) clinical or biochemical suspicion (procalcitonin $>0.5 \mathrm{ng} /$ $\mathrm{mL}$ ) of active infection other than with SARS-CoV-2; 10) management as an outpatient; 11) conservative or palliative management; 12) participation in another clinical trial; or 13) any major uncontrolled medical, psychological, psychiatric, geographic or social problem that contraindicates the patient's participation in the trial or hinders (Continued on next page)
\end{abstract}

\footnotetext{
* Correspondence: ilesbujanda@gmail.com

'Internal Medicine Department, Complejo Hospitalario de Navarra, Pamplona, Spain

Full list of author information is available at the end of the article
}

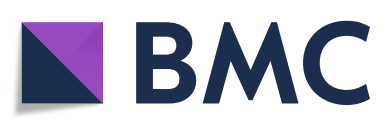

(c) The Author(s). 2021 Open Access This article is licensed under a Creative Commons Attribution 4.0 International License, which permits use, sharing, adaptation, distribution and reproduction in any medium or format, as long as you give appropriate credit to the original author(s) and the source, provide a link to the Creative Commons licence, and indicate if changes were made. The images or other third party material in this article are included in the article's Creative Commons licence, unless indicated otherwise in a credit line to the material. If material is not included in the article's Creative Commons licence and your intended use is not permitted by statutory regulation or exceeds the permitted use, you will need to obtain permission directly from the copyright holder. To view a copy of this licence, visit http://creativecommons.org/licenses/by/4.0/. The Creative Commons Public Domain Dedication waiver (http://creativecommons.org/publicdomain/zero/1.0/) applies to the data made available in this article, unless otherwise stated in a credit line to the data. 
(Continued from previous page)

proper follow-up and adherence to the protocol and evaluation of study outcomes.

Intervention and comparator: Eligible patients will be randomised to receive standard of care plus methylprednisolone (intervention group) or standard of care plus placebo (control group).

- Intervention group: standard of care at the discretion of the researcher, including lopinavir/ritonavir (200/50 mg, 2 tablets twice daily, per os, for 7 to 14 days) \pm remdesivir (a single intravenous loading dose of 200 mg on day 1 followed by once-daily intravenous maintenance doses of $100 \mathrm{mg}$ from day 2 to 5), or no drug treatment, + methylprednisolone (once-daily intravenous infusion of $120 \mathrm{mg}$ on days 1, 2 and 3).

- Control group: standard of care at the discretion of the researcher, including lopinavir/ritonavir (200/50 mg, 2 tablets every 12 hours, per os, for 7 to 14 days) \pm remdesivir (a single intravenous loading dose of $200 \mathrm{mg}$ on day 1 followed by once-daily intravenous maintenance doses of $100 \mathrm{mg}$ from day 2 to 5), or no drug treatment, + placebo (once-daily intravenous infusion of $100 \mathrm{~mL}$ of $0.9 \%$ saline on days 1, 2 and 3).

Main outcomes: The primary outcome is the proportion of patients with treatment failure at 14 days after randomisation, defined as: 1) death, 2) need for admission to an intensive care unit (ICU), 3) initiation of mechanical ventilation, 4) $\mathrm{SpO}_{2}$ falling to $<90 \%$ (in ambient air) or $\mathrm{PaO}_{2}<60 \mathrm{mmHg}$ (in ambient air) or $\mathrm{PaO}_{2} \mathrm{FiO}_{2}<300 \mathrm{mmHg}$, not explained by a cause other than COVID-19, and/or 5) decrease in $\mathrm{PaO}_{2} \geq 15 \%$ from baseline, together with laboratory and radiological deterioration.

Randomisation: Treatment will be allocated by block randomisation stratified by patient age ( $<$ or $\geq 75$ years of age). For this purpose, we will use the $\mathrm{R}$ randomizeR package using two block sizes (4 and 6) with random permutation. The randomisation sequence will be generated by a unit (the Navarrabiomed Clinical Trials Platform) independent from the researchers who will recruit patients and implement the protocol.

Blinding (masking): The study will be quadruple-blinded, specifically, with blinding of patients, intervention providers, outcome assessors and data managers. The pharmacy at each participating hospital will prepare indistinguishable bags of methylprednisolone or placebo ( $0.9 \%$ saline) for patients of the experimental and placebo groups, respectively.

Numbers to be randomised (sample size): The percentage of patients with treatment failure (primary endpoint) is currently unknown. Assuming an absolute difference of $25 \%$ in the primary outcome between the two groups (35\% in the control group and $10 \%$ in the intervention group), we estimate that 60 patients (30 per group) are required to detect this difference with a two-tailed type I error of 0.05 and a type II error of 0.2. Estimating a loss to follow-up of 20\%, we should recruit a total sample size of 72 patients (36 per group).

Trial Status: The Spanish Agency of Medicines and Medical Devices (AEMPS) and the Ethics Committee of the University Hospital La Princesa approved version 7.0 of the protocol on 30 April 2020 as a low intervention clinical trial. Subsequently, the protocol has been amended by researchers and re-approved by AEMPS and the same ethics committee on 1 July 2020 (version 8.0) and on 28 August 2020 (version 9.0). Currently, the trial is in the recruitment phase. Recruitment began on 28 May 2020 and is expected to be completed by February 2021.

Trial registration: This study protocol was registered on the eudract.ema.europa.eu on 5 May 2020 (title "Early treatment of COVID-19 pneumonia with glucocorticoids. Randomized controlled clinical trial"; EudraCT Number: 202 0-001827-15) and on clinicaltrials.gov on 19 June 2020 (title: "Glucocorticoids in COVID-19 (CORTIVID)"; identifier: NCT04438980).

Full protocol: The full protocol (version 9.0) is attached as an additional file, accessible from the Trials website (Additional file 1). In the interest in expediting dissemination of this material, the familiar formatting has been eliminated; this Letter serves as a summary of the key elements of the full protocol.

Keywords: COVID-19, Randomised controlled trial, protocol, SARS-CoV-2, Pneumonia, Quadruple blind, Glucocorticoids, Methylprednisolone, Pulses, Early treatment 


\section{Supplementary Information}

The online version contains supplementary material available at https://doi. org/10.1186/s13063-020-04999-4.

Additional file 1. Full Protocol.

\section{Acknowledgements}

Authors are grateful to Ideas Need Communicating Language Services for help editing the manuscript.

\section{Authors' contributions}

I.L.B. conceived the study, led the proposal and protocol development. J.L.A., F.C.B., I.E.G., J.A.S. and A.M.S. contributed to study design and to development of the proposal. J.L.L. was the lead trial methodologist. I.L.B., J.L.A., F.C.B., I.E.G. and J.A.S. wrote the original protocol draft. R.G.R. and J.S.A reviewed the original draft and supervised the study. All authors contributed to writing the structured summary. All authors read and approved the final manuscript.

\section{Authors' information}

Not applicable.

\section{Funding}

This research received funding from Navarrabiomed for the English translation of the protocol. No further funding was obtained to assist with the study design, collection, analysis and interpretation of data and writing of the manuscript.

\section{Availability of data and materials}

Not applicable.

\section{Ethics approval and consent to participate}

This clinical trial will be carried out in accordance with the ethical principles of the most recent revision of the Declaration of Helsinki and current legislation. The original and revised versions of the protocol, information sheet and informed consent form have been approved by the clinical research ethics committee (CREC) of University Hospital La Princesa and the Spanish Agency of Medicines and Medical Devices (AEMPS) (approval of the latest version being granted on 28 August 2020, reference number: 17092020_08400, locator: QFSS36Q6C5). For further information, the following link to the public listing of the ethical approval is available: https:// localizador.aemps.es/localizador/localizador.do. The researchers certify that this trial has received ethical approval from the appropriate ethical committee as described above.

The researchers will be in charge of providing each patient or their legal representative with the patient information sheet and informed consent form. Individuals participating in the trial or their legal representative will be asked to sign and date the informed consent form prior to inclusion in the study, that is, before the performance of any intervention.

\section{Consent for publication}

Not applicable.

\section{Competing interests}

The authors declare that they have no competing interests.

\section{Author details}

Internal Medicine Department, Complejo Hospitalario de Navarra, Pamplona, Spain. ${ }^{2}$ Internal Medicine Department, Hospital Moisès Broggi, Consorci Sanitari Integral, Sant Joan Despí, Barcelona, Spain. ${ }^{3}$ Hospital Pharmacy Department, Complejo Hospitalario de Navarra, Pamplona, Spain. ${ }^{4}$ Hospital Pharmacy Department, Hospital Moisès Broggi, Consorci Sanitari Integral, Sant Joan Despí, Barcelona, Spain. ${ }^{5}$ Clinical Trials Platform, Navarrabiomed, Complejo Hospitalario de Navarra, Universidad Pública de Navarra, Instituto de Investigación Sanitaria de Navarra, Pamplona, Spain. ${ }^{6}$ Methodology Unit, Navarrabiomed, Complejo Hospitalario de Navarra, Universidad Pública de Navarra, Instituto de Investigación Sanitaria de Navarra, Pamplona, Spain.

Received: 19 December 2020 Accepted: 23 December 2020 Published online: 11 January 2021

\section{Publisher's Note}

Springer Nature remains neutral with regard to jurisdictional claims in published maps and institutional affiliations.

\section{Ready to submit your research? Choose BMC and benefit from:}

- fast, convenient online submission

- thorough peer review by experienced researchers in your field

- rapid publication on acceptance

- support for research data, including large and complex data types

- gold Open Access which fosters wider collaboration and increased citations

- maximum visibility for your research: over $100 \mathrm{M}$ website views per year

At BMC, research is always in progress.

Learn more biomedcentral.com/submissions 